\title{
Acreditación de alta calidad, mi compromiso
}

\section{PhD. Héctor Jaime Dulcé Moreno}

Esta afirmación se está convirtiendo en un sentimiento compartido por toda la comunidad que hace parte de la Universidad Francisco de Paula Santander, sin importar el estamento al que se pertenezca, cada individuo participa con mayor o menor grado de responsabilidad, en la construcción colectiva de las acciones necesarias para el logro de los indicadores exigidos, o de planes de mejoramiento que garanticen un alto grado de calidad de los procesos que desarrolla la Institución, en cumplimiento de ejes misionales; es decir: docencia, investigación y extensión.

En Colombia, a partir de la formulación de la ley de educación superior (Ley 30 de 1992), se implementó un Sistema Nacional de Acreditación del cual hace parte el Consejo Nacional de Acreditación (CNA), el cual establece a través del Consejo Nacional de Educación Superior (CESU) las políticas y planes para el desarrollo de la Educación Superior; éste organismo con funciones de coordinación, planificación, recomendación y asesoría está integrado por representantes de todos los sectores relacionados con la educación superior y la evaluación de requisitos mínimos, para la creación de instituciones de educación superior y de programas académicos, la realiza la Comisión Nacional para el Aseguramiento de la Calidad de la Educación Superior (CONACES).

La evaluación tendiente a la acreditación se realiza en tres etapas: La autoevaluación: Proceso permanente que se desarrolla internamente, por cada institución o programa académico, se basa en el modelo de acreditación establecido por el CNA. En esta etapa, la institución refleja su compromiso con la calidad. Se espera que los resultados de la autoevaluación sean útiles no sólo a los fines de la acreditación, sino en la formulación y desarrollo de acciones para mejoramiento continuo de la calidad de los programas académicos. La Evaluación Externa o Evaluación por Pares: Es realizada por pares académicos, designados por el CNA, quienes verifican la coherencia entre lo que presenta el informe de autoevaluación y lo que efectivamente se encuentran en la institución. Los pares emiten sus juicios de calidad basados en la información suministrada, incluso en aquellos aspectos que no fueron considerados en la autoevaluación y que de igual forma resultan relevantes para apreciar la calidad de las instituciones y/o programas. La Evaluación final: Corresponde al concepto final emitido por el CNA, basado en la autoevaluación del programa, en el informe entregado por el equipo de pares y en la posición de la institución con respecto a dicho informe. Este concepto técnico se traslada al Ministro de Educación Nacional para la expedición del acto de acreditación.

Para iniciar el proceso de acreditación se requiere de la voluntad expresa de la institución ante el CNA, además se debe cumplir con ciertas condiciones esenciales. En lo académico los requisitos se orientan a la disposición de una Misión claramente definida en el marco del Proyecto Institucional, contar con un cuerpo profesoral apropiado, varias promociones de egresados y una infraestructura adecuada; en lo administrativo requiere de una estructura organizacional, con sistemas de gestión y administración y recursos financieros necesarios. Cumplida esta fase documental, el CNA realizará una visita de verificación de condiciones iniciales a la institución, en la cual se recomendará la continuidad ó no del proceso. En el documento "La Educación Superior en Colombia: Situación Actual y Análisis de Eficiencia” elaborado por Ligia Alba Melo B., Jorge Enrique Ramos F., y Pedro Oswaldo Hernández S. se considera que los principales indicadores del sector son: cobertura, deserción, número y calificación de docentes, financiación de las instituciones públicas y resultados del logro académico, por lo que se hace necesario tenerlos muy en cuenta.

Un primer paso se da, por parte del Consejo Superior Universitario, con la revisión y reformulación de la misión y visión institucional (Acuerdo 007 del 27 de febrero de 2015), posteriormente se avanza con la adopción de una nueva política de Alta Calidad (Acuerdo 106 del 26 de diciembre de 2016); seguido de la coordinación de acciones conjuntas entre los diferentes estamentos universitarios tendientes a la acreditación de alta calidad de un porcentaje de los programas que oferta la institución, tanto en la sede central en Cúcuta como en la seccional de Ocaña, requisito para la Acreditación Institucional Multicampus.

Comprometidos con el proceso de acreditación, entre el 18 de enero y 14 de febrero de 2017, los docentes de la universidad asistieron al Taller de Desarrollo Profesoral, en el cual se generaron espacios de reflexión, y se compartieron conocimientos e intercambiaron experiencias con representantes de entidades reconocidas a nivel nacional. En las conferencias se trataron temáticas de actualidad y relevancia para los procesos de Acreditación de Alta Calidad. A continuación se presenta algunas de ellas.

En la actualidad los programas, de la Universidad Francisco de Paula Santander, que buscan la acreditación de alta calidad se encuentran desarrollando la primera etapa; por lo que se hace necesario la colaboración de todos los actores de nuestra Institución en busca de un objetivo común: la acreditación Institucional, y con ello el logro de la Visión Institucional: “el reconocimiento a nivel Nacional por la alta calidad, competitiva y pertinencia de sus programas académicos, la generación de conocimiento, la transferencia de ciencia y tecnología, y la formación de profesionales con sentido de responsabilidad social, utilizando estrategias metodológicas presenciales, a distancia y virtuales, que faciliten la transformación de la sociedad desde el ámbito local hacia lo global”. 